\title{
Urban Sprawl in Wadi Goss Watershed (Jeddah City/Western Saudi Arabia) and Its Impact on Vulnerability and Flood Hazards
}

\author{
Ashi Azzam, Atef Belhaj Ali \\ Department of Geography and GIS, Faculty of Arts and Humanities, King Abdulaziz University, Jeddah, KSA \\ Email: amalhabeb@kau.edu.sa
}

How to cite this paper: Azzam, A. and Belhaj Ali, A. (2019) Urban Sprawl in Wadi Goss Watershed (Jeddah City/Western Saudi Arabia) and Its Impact on Vulnerability and Flood Hazards. Journal of Geographic Information System, 11, 371-388. https://doi.org/10.4236/jgis.2019.113023

Received: April 10, 2019

Accepted: June 22, 2019

Published: June 25, 2019

Copyright () 2019 by author(s) and Scientific Research Publishing Inc. This work is licensed under the Creative Commons Attribution International License (CC BY 4.0).

http://creativecommons.org/licenses/by/4.0/

\begin{abstract}
Today, climate change imposes enormous challenges on a global scale. The interactions of the balances between the need for development, population growth, massive urbanization generate a negative impact on the presence of these climate changes. One of the direct consequences of these changes is the phenomenon of flash floods, a phenomenon that hit the city of Jeddah (city located in west of Saudi Arabia) twice, one in 2009 and the other in 2011, causing significant human and material damage. Floods are considered as a direct result of the combination of extreme weather and hydrological phenomena; in most cases, the magnitude of these floods is magnified by anthropogenic factors, which increases the risk. According to the risk triangle, risk is defined as a probabilistic function that depends on three essential elements: exposure, vulnerability and hazard. If any of these three elements undergo growth the risk also does so and vice versa. Exposure and vulnerability will depend on the presence of human activities in the study area. This study is conducted on the Wadi Goss watershed as it was one of the most violent basins during the 2009 and 2011 floods. Indeed, we present in this study the extent of the urban extension in the Wadi Goss watershed, since 1984 to days and this by the using Landsat images. Given the nature of the study area, we present a method based on the calculation of various indices followed by a classification operation in order to define the urbanized zones inside the Wadi Goss watershed and then estimate the urban sprawl inside the watershed. We also present in this paper, the characteristics of the watershed as well as the evolution of the urbanized areas exposed to the phenomenon of floods and their contribution to the changes of the hydrological behavior of the basin, and to increase the evolution of the risk of the floods. We have shown through this study that the urban footprint has increased from 90 hectares in 1985 to 850 hectares in 2015. This urban footprint represents $12 \%$ of the total
\end{abstract}


area of the watershed. Most of the urban evolution was operated on the wadi area with a concentration in the western part of the basin and especially at its outlet.

\section{Keywords}

Flood Hazards, Jeddah, GIS, Remote Sensing, Urban Sprawl, Risk, Saudi Arabia

\section{Introduction}

Jeddah is the second largest city in Saudi Arabia with a population of around 3.5 million, containing about $14 \%$ of the total population of Saudi Arabia. It is located in the west coast of Saudi Arabia at latitude $29.21^{\circ}$ North and longitude $39.7^{\circ}$ East (Figure 1). The city has a leading role in economic and tourist activities and is considered an international economic city and a business center. The proportion of foreigners is about $51 \%$ of the total population in Jeddah; this percentage shows that the city of Jeddah is suitable for business and commerce. The total area of the municipality of Jeddah is $5460 \mathrm{~km}^{2}$; its urban area covers an area of $1765 \mathrm{~km}^{2}$.

The city of Jeddah dates back nearly 3000 years and was created by a group of fishermen as a refuge in which they rested after the fishing campaigns; since the advent of Islam in the Arabian Peninsula, the history of the city of Jeddah has been significantly associated with the development of Islamic history and has been regarded as the gateway to the Two Holy Mosques (mosques of Mecca and Medina).

The climate of Jeddah is characterized by high temperatures (Figure 2) and humidity during the summer months with temperatures reaching 40 degrees Celsius. This is because of warm air masses with the highest levels of moisture in summer because rising sea temperatures go down in the winter.

Winds in the city of Jeddah are generally northwesterly in direction, usually light to moderate on most days of the year. During the winter, spring and autumn months, the winds are southerly in direction and this results in a rise in temperature. The winds sometimes activate sand and dust storms which are also accompanied by thunderstorms and heavy rain. However, most of the rain are light accompanied by thunderstorms usually during the winter months i.e., mainly in November, December and January, but also in the spring and autumn resulting from the passage of air depressions from west to east. Figure 3 illustrates monthly mean of rainfalls measured in Jeddah airport station between 2005 and 2014.

Located in the foothills of a mountain range, east of the city of Jeddah is diversion of several watersheds as shown in Figure 4. In this study, we focus on Wadi Goss watershed (basin \#11, Figure 4) that had more influence on the city of Jeddah and which caused the most damage especially during the floods of 2009 and 2011. 


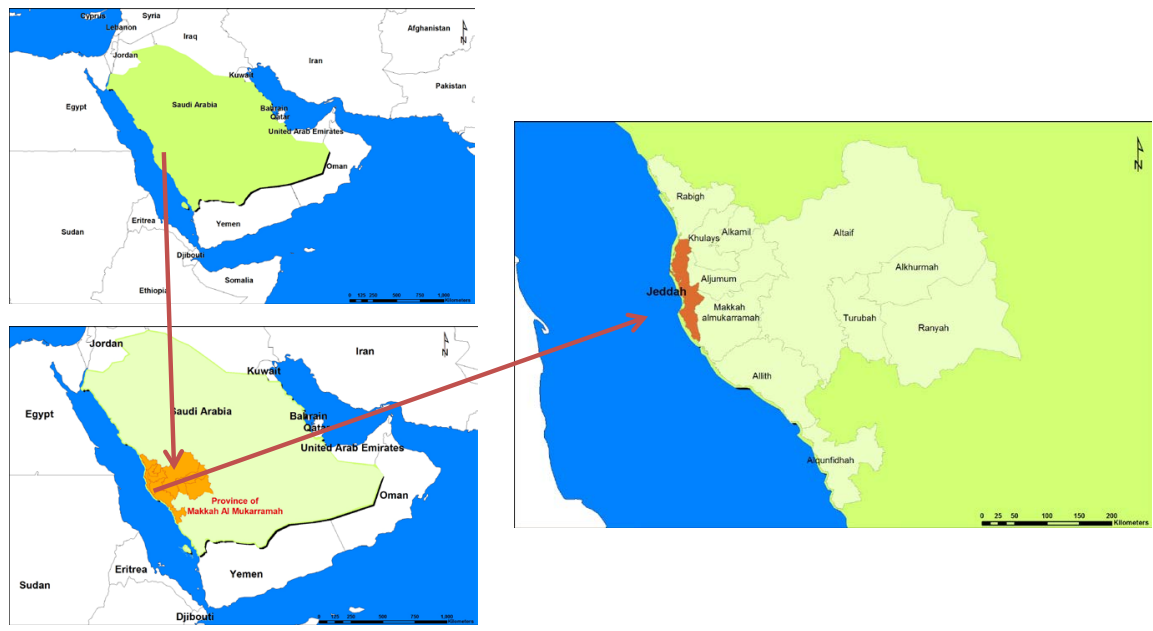

Figure 1. Location of Jeddah city.

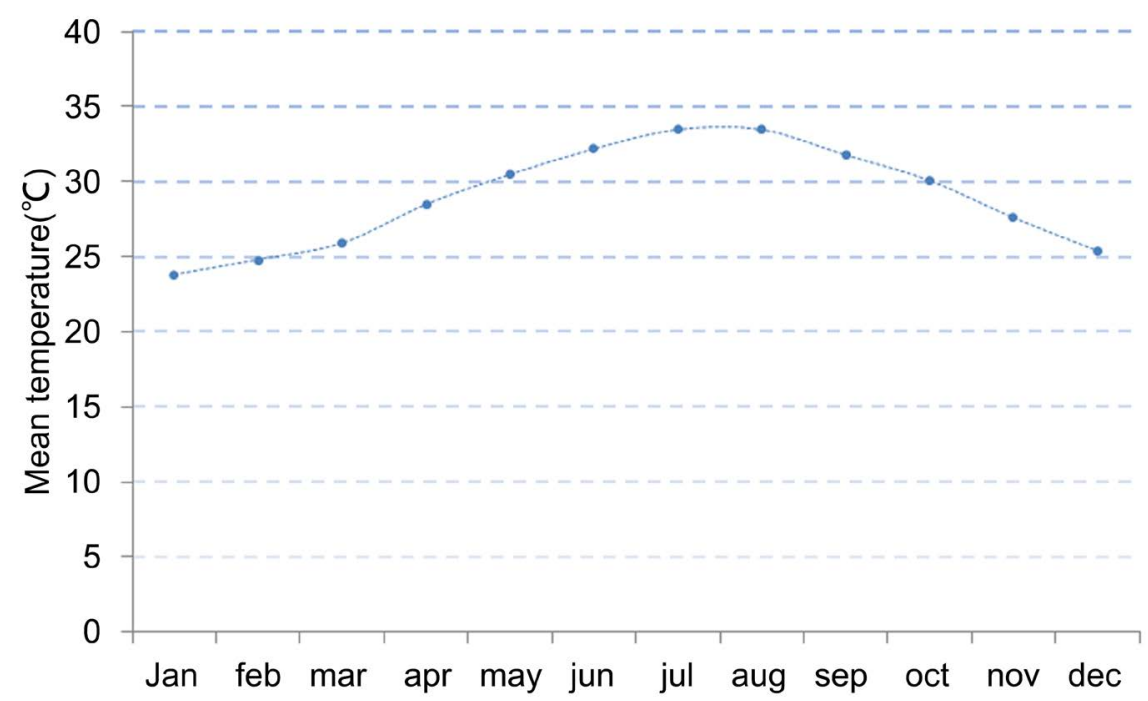

Figure 2. Temperatures in Jeddah.

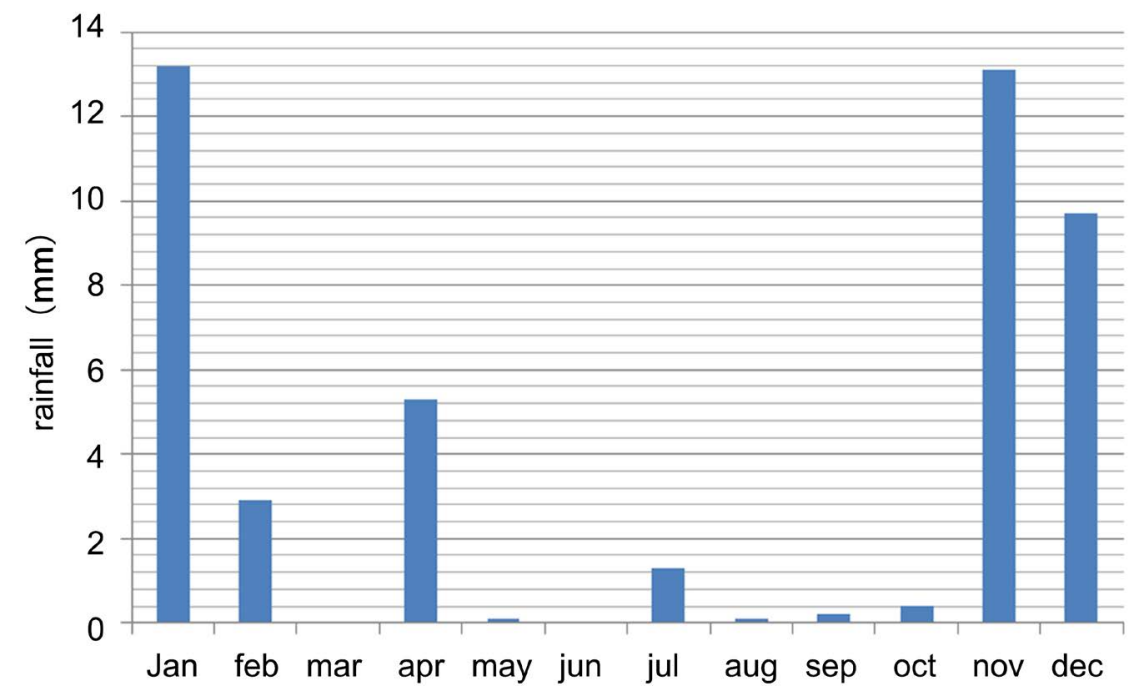

Figure 3. Monthly mean rainfall in Jeddah between 2005 to 2014 . 


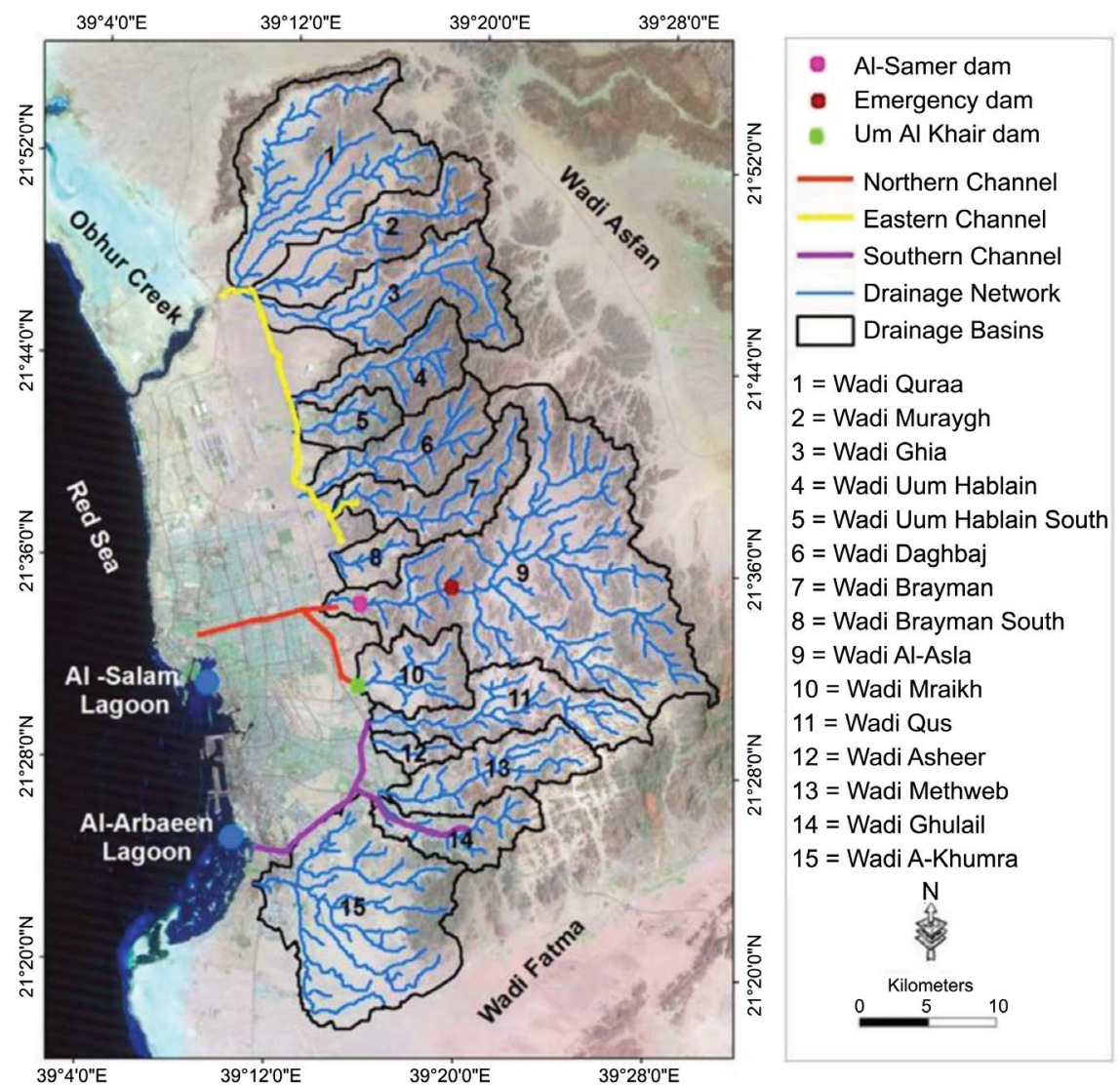

Figure 4. Watersheds located at east of Jeddah city [1].

\section{The City of Jeddah and the Floods}

The statistical overview put in place by the international database on disasters [2], shows that human damage recorded in Saudi Arabia in different natural disasters over the last 25 years was 299 people (between 1982 and 2005). This reveals the magnitude of the impact of the flood disaster that occurred in 2009. A year later, in January 2011, another flood event occurred and covered a larger geographic area. It has also caused damage and many people have been killed, lost or injured [3].

In fact, the western part of the Arabian Peninsula is a mega-structure, in which the mountain ranges are oriented in the NW-SE direction. Along this mountainous region, surface runoff is almost diverted to the Red Sea to the west. Thus, several topographic units exist to capture the rainwater between them. Rainfall in the western part of the Arabian Peninsula is low (below $200 \mathrm{~mm}$ ), but a number of drainage systems occur and operate an extensive drainage network [4].

That said, Saudi Arabia is an ideal example of natural hazards, and has become a region of natural risk. This is well pronounced, since the region is exposed to changes in its climatic condition, and in particular the increase in the amount of rainfall. The most common natural phenomena are dust storms, floods and mudslides, while the region is also vulnerable to many other aspects 
of natural hazards, such as erosion, drought, earthquake, volcanoes etc. These dangerous events are physically controlled and their impact has increased where dense human activities are developed [5].

Jeddah was flooded after a heavy rain on November 25, 2009. The city suffered $90 \mathrm{~mm}$ showers of rain fell in four hours. The death toll was 161, with damage to 8000 homes and more than 7000 vehicles, the photos in Figure 5 show the extent of the damage. The largest amount of rain was between 9 am to $3 \mathrm{pm}$ as shown by remote sensory data provided by Tropical Rainfall Measuring Mission (TRMM) satellites (Figure 6).

On Wednesday 26 January 2011, the rainfall rate was $111 \mathrm{~mm}$, flood have been going from east to west reached the Red Sea cutting off $13 \mathrm{~km}$ from the center of Jeddah with great force. The floods swept over $80 \%$ of the Jeddah area from roads, streets and buildings. 400 to $600 \mathrm{~km}^{2}$ in the amount of 102 to 120 $\mathrm{mm}$, which means that the total rainfall of 6 to 9 billion cubic meters of water that is large amount of the city often occur rain. Jeddah city suffered losses in human and property due to heavy rain lasted for 3 - 4 hours was the cause of the disaster floods and may be the most important reasons is the lack of good planning in the past as some of the houses were located on the flood area and also the city does not have the channels or drainage networks can face this rain.

In Saudi Arabia, precipitation has a very small total amplitude during a specific time interval and is unpredictable with irregular but very intense local storms. The southwestern region is in the subtropical climate zone of Saudi Arabia and receives the greatest amount of rainfall compared to other regions, as it is mountainous with altitudes of over $2000 \mathrm{~m}$ [6].

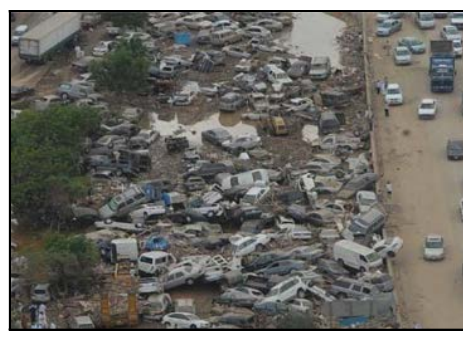

(a)

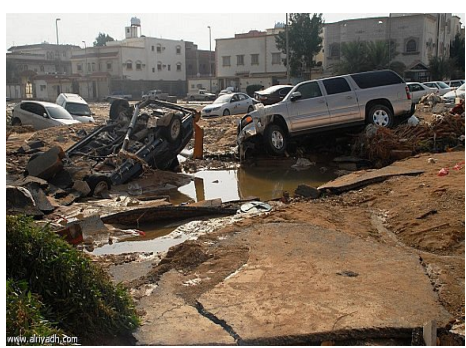

(c)

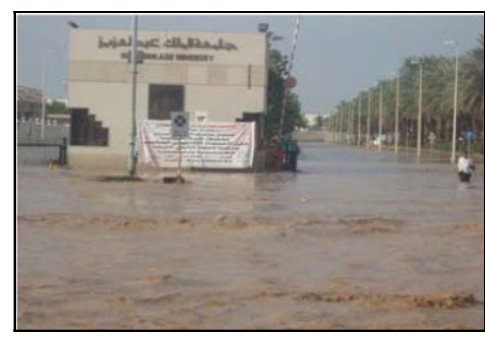

(b)

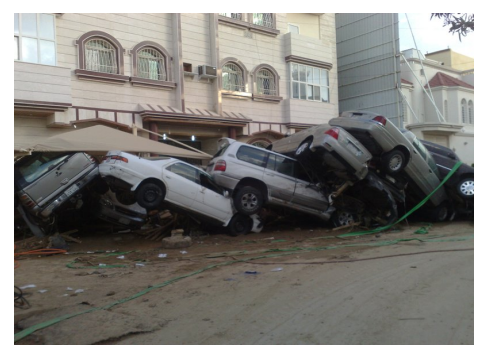

(d)

Figure 5. 2009 and 2011 flood damage. (a) Guwaizah and Al-Haramain Roads 2009; (b) Abdullah Sulayman Gate, King Abdulaziz University, 2009; (c) (d) Urban Area East of Jeddah (2011). 


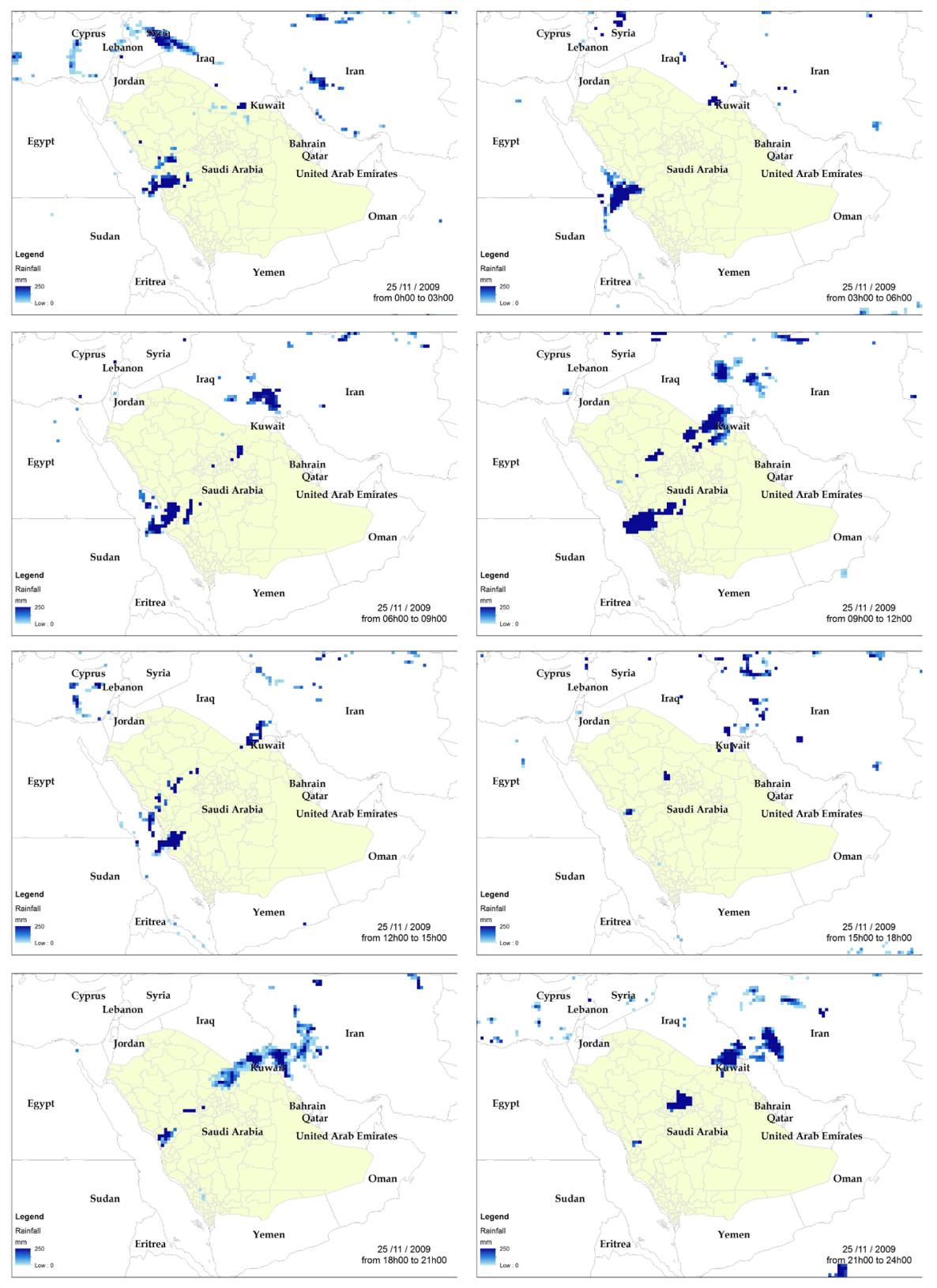

Figure 6. Rainfall measures by TRMM satellites.

\section{Study Area and Theoretical Framework of the Study}

\subsection{Study Area}

The study area (Wadi Goss Watershed) consists of an upper watershed and a lowland plain east of the city of Jeddah as shown in Figure 7, latitudes $21.5^{\circ}$ North and longitude $39.3^{\circ}$ East. The catchment area covers an area of approximately $63 \mathrm{~km}^{2}$. Therefore, the lower land of the plain has a gradient of $0 \%-2 \%$ slope that makes the area susceptible to flooding during the winter season that begins in November and the end of March. The sustained and sometimes poorly controlled urban development of Jeddah has brought neighborhoods to flood zones, this is one of the main reasons for the rain disaster in Jeddah in 2009-2011. 


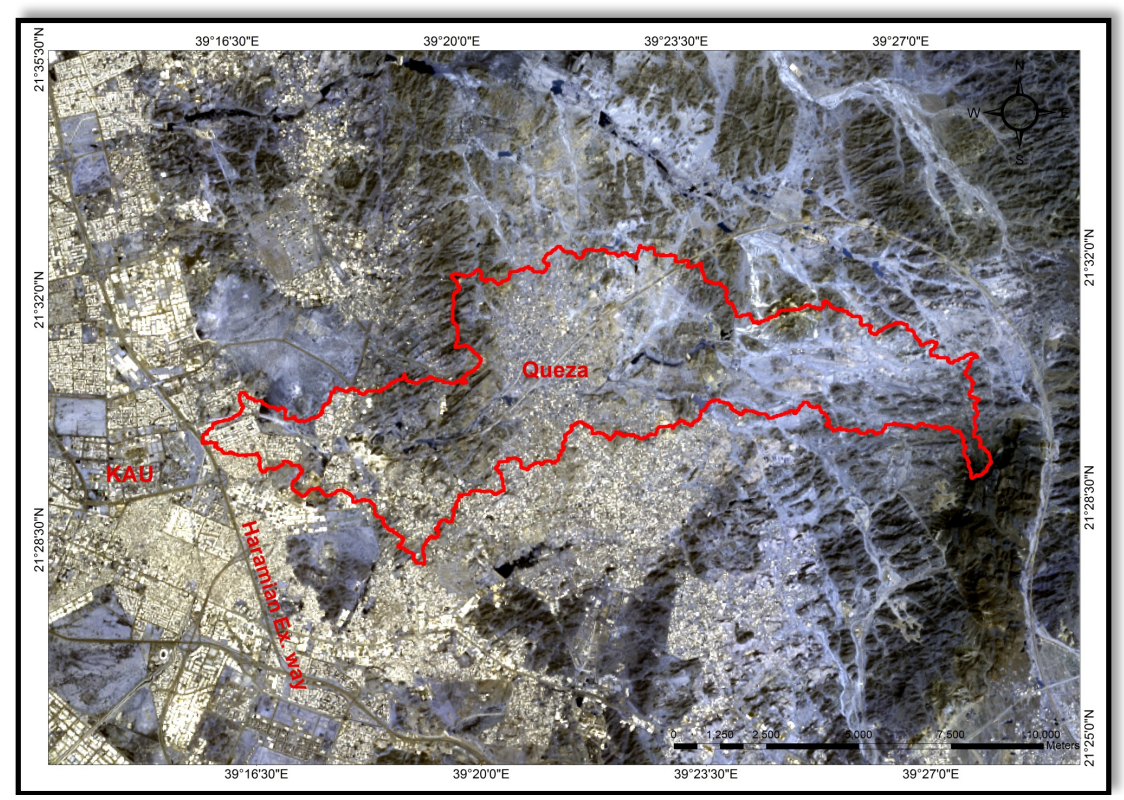

Figure 7. Study area (Wadi Goss watershed).

The western part of the study area is the part that suffered the violent floods of 2009 and 2011, which led the authorities to take measures to protect the city of Jeddah against floods two large rainwater drainage channels and a dam for the retention of water from the east.

Indeed, we are focusing on the eastern part, since the western part is protected against floods and even if there still remains fears of floods which are due mainly to the absence of a drainage network covering the entire city. Except for some neighborhoods, rainwater is discharged in a superficial way through the road network.

\subsection{Theoretical Framework of the Study}

Floods can be caused by a number of processes, but the dominant cause is often rainfall. Floods are a natural process often aggravated by human activities. Floods occur at irregular intervals and vary in power, the extent of the damaged area, and the duration.

Each flood is different. They can happen suddenly, or can take days, even months to disappear and unload. They occur at often irregular intervals.

However, the notion of risk cannot be defined without defining the notion of vulnerability and exposure. The notion of vulnerability in this definition does not distinguish between the mere physical exposure to risks on the one hand and the sensitivity of people or things to risks on the other. We adopt the following definition of a risk (Figure 8):

"Risk is the probability of a loss that depends on three things: hazards, vulnerability, and exposure, and if one of these three elements increases or decreases, the risk increases or decreases, respectively." [7]

$$
\text { Risk }=\mathrm{f}(\text { Hazards } \times \text { Exposure } \times \text { vulnerability })
$$




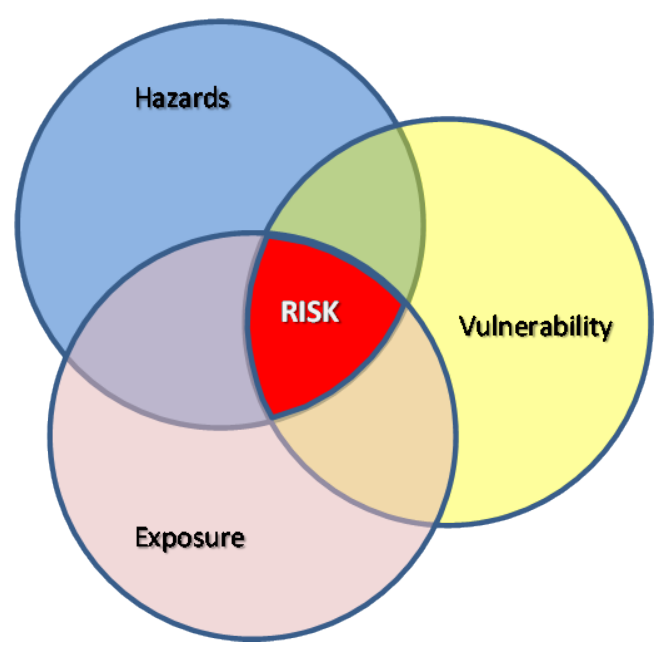

Figure 8. Definition of risk.

Although exposure refers in the context of floods only to the question of whether people or property are physically in the floodway or not, vulnerability can be defined as "conditions determined by factors or physical, social, economic and environmental processes that increase a community's sensitivity to the impact of risks." Thus, risk can be considered as a combination of these 3 factors: hazard, vulnerability and exposure.

We are interested in the exposure component by studying urban extension in the study area and its proximity to major watercourses and water accumulation zones during floods. Indeed; urbanization significantly affects the flow of surface water as shown in Figure 9.

\subsection{Watershed Characterization}

In order to understand the hydrological functioning and drainage morphometry of the watershed we have calculated some indicators to better characterize it. These characteristics are recorded in Table 1. It appears that the drains of the watershed have a high order as well as a drainage density and a relatively large bifurcation rate. These features make it one of the most dangerous-watersheds in the study area, and its contribution to the 2009 and 2011 floods was bad. To classify the hydrographic network, we adopt the Strahler classification. The results of this classification are shown in Figure 10.

\subsection{Study of Urban Sprawl inside the Watershed}

Urban expansion and its link with risks has been the subject of several studies. Francesco Faccini, et al. had studied the role of the rain and the flood in genova in 2014 [8]. MeirongSu \& al analyze the relationship between landscape patterns and the risk of urban water logging and flood disaster [9]. Boulomytis V. T et al. had demonstrated through the analysis the effect of urbanization and its direct impact to increase of flood susceptibility in coastal areas [10]. To follow the evolution and the urban extension in the study area, we used the images of the 
Table 1. Main characteristics of Wadi Goss Watershed.

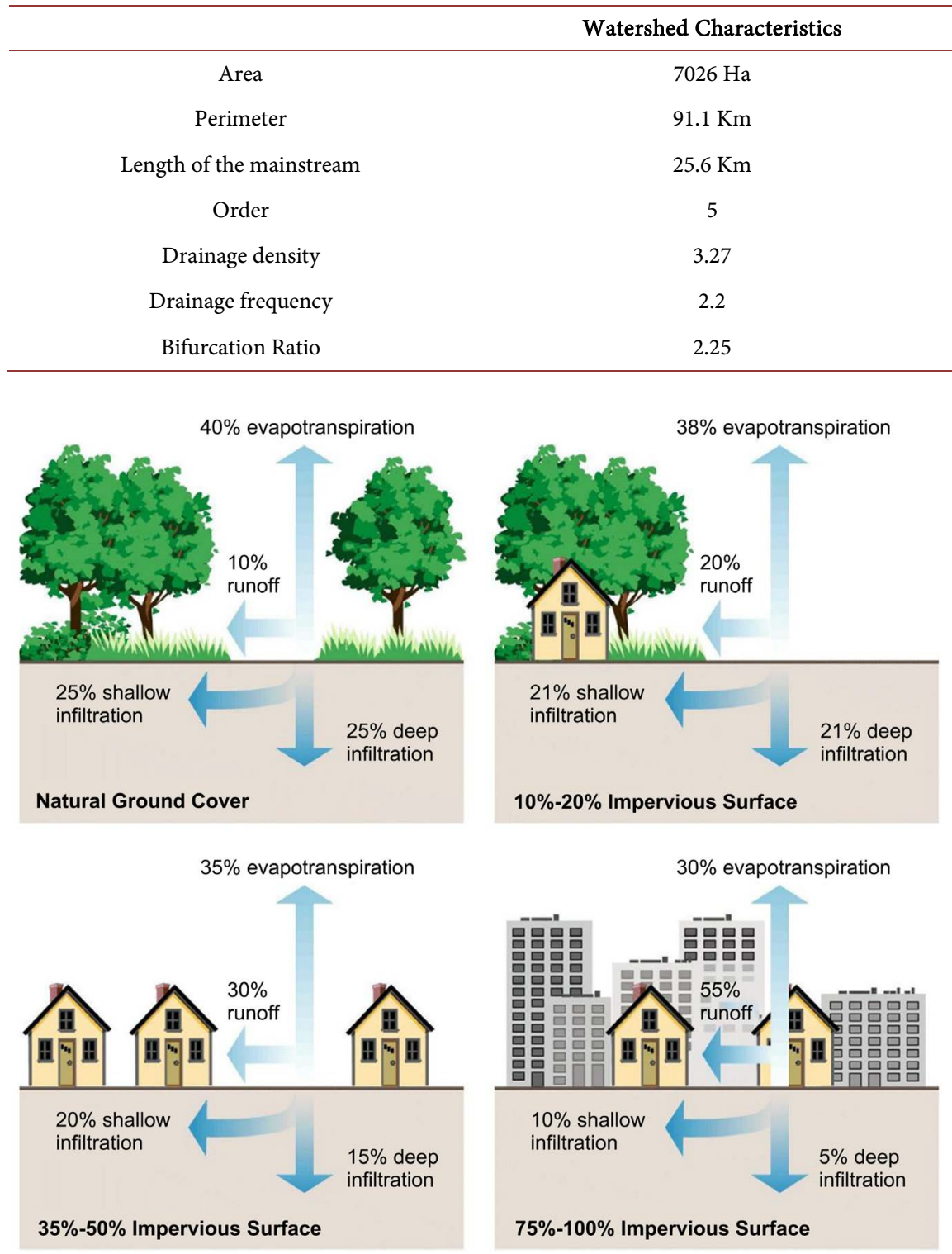

Figure 9. The influence of urbanization on different components of the water cycle (source: USDA).

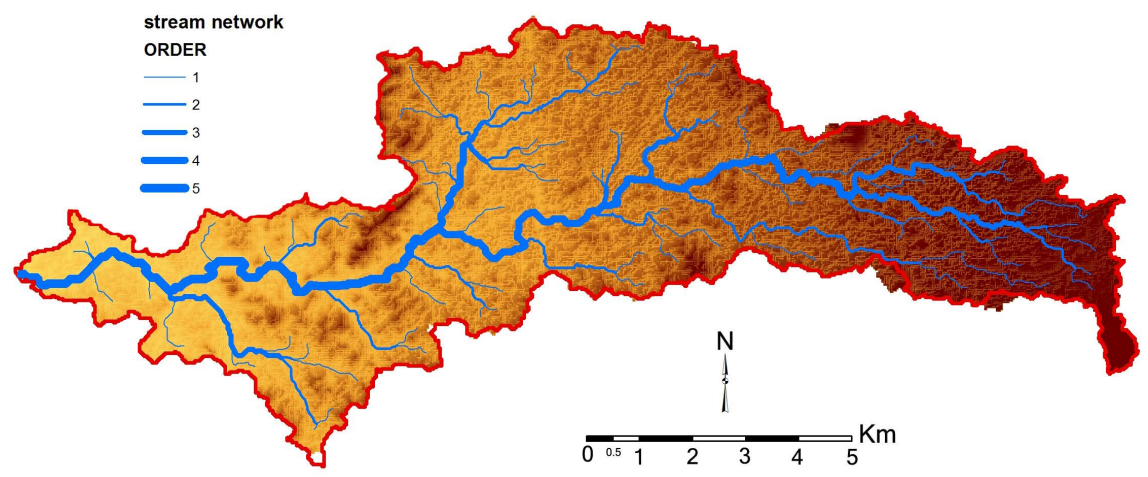

Figure 10. Strahler classification of the stream network. 
Landsat satellites. Although they are of medium resolution, we have moved towards the choice of this type of image given their availability as well as the presence of a series of images dating back to the 80s. Table 2 illustrates the images used for monitoring urban dynamics.

We try to classify images by using a supervised classification technique and by setting of training parcels (Figure 11), the result obtained shows that there is a confusion between the built-up areas and the rocky mountains located at the east of the study area. This confusion persists despite densification of training parcels and this is due to the similarity of spectral signatures between urban areas and rocky mountains (Figure 12). Given this confusion the supervised classification method was unsatisfactory (Figure 13). For this purpose, we propose the following method which consists of:

1) generate indices from the initial channels of the images

2) compose a new image using these neo-channels

3) perform an unsupervised classification of the new image

4) extract classes representing urban areas

An urban area is considered as a complex ecosystem composed of heterogeneous materials. Our study area can be considered as a peri-urban ecosystem mainly composed by urban areas, vegetation, bare soil (with different levels of humidity). Since the pixel-based classification based on the use of the original

Table 2. LandSat images.

\begin{tabular}{lcc}
\hline & Satellite & Date \\
\hline $\mathbf{1}$ & Landsat 5 TM & $09 / 06 / 1985$ \\
$\mathbf{2}$ & Landsat 5 TM & $09 / 09 / 1990$ \\
$\mathbf{3}$ & Landsat 5 TM & $17 / 03 / 1995$ \\
$\mathbf{4}$ & Landsat 5 TM & $22 / 09 / 2000$ \\
$\mathbf{5}$ & Landsat 7 ETM & $04 / 03 / 2005$ \\
$\mathbf{6}$ & Landsat 7 ETM & $18 / 03 / 2010$ \\
$\mathbf{7}$ & Landsat 8 OLI/TIRS & $31 / 08 / 2014$ \\
\hline
\end{tabular}

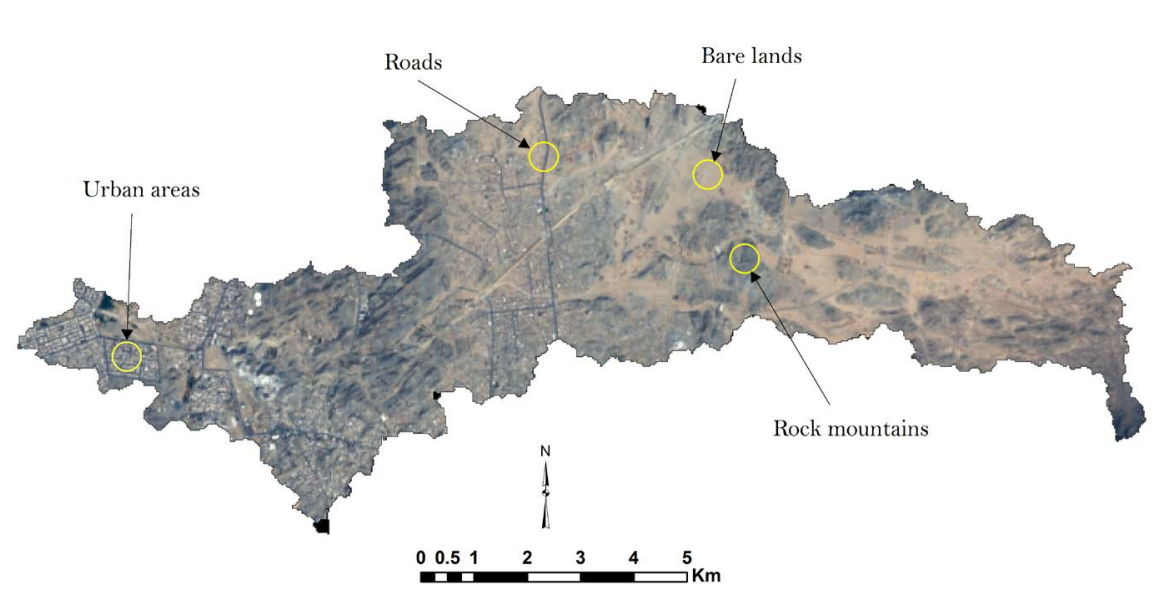

Figure 11. Training parcels for the supervised classification process. 


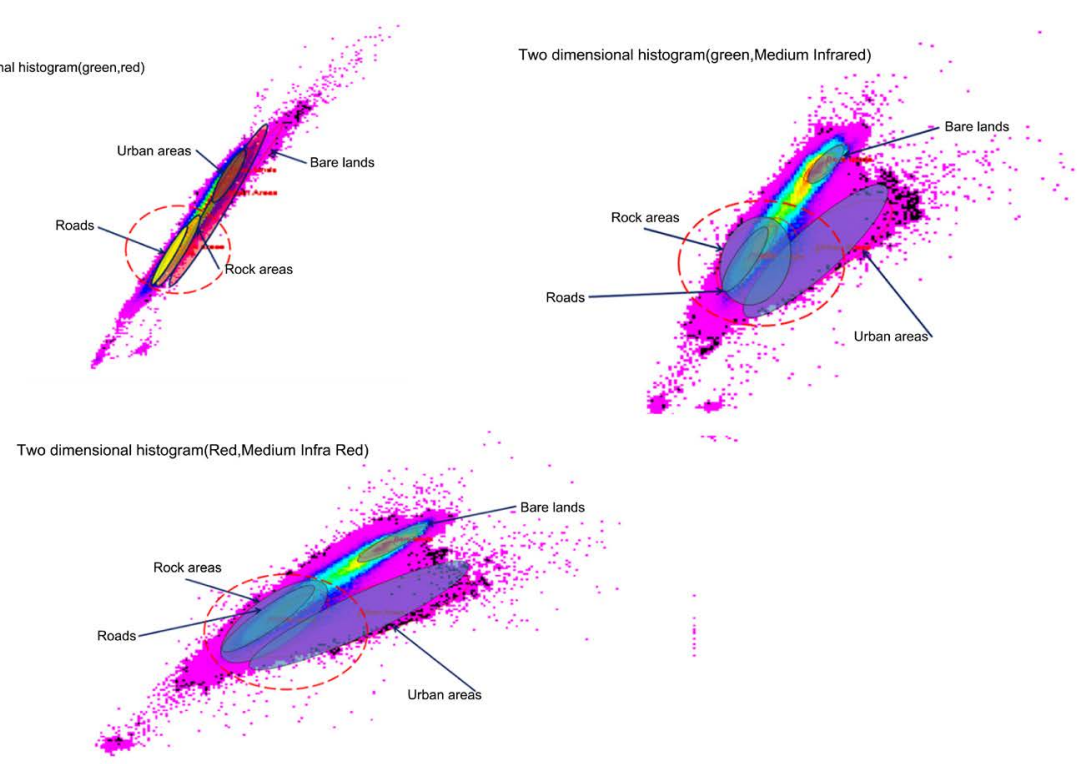

Figure 12. Scatterplots between the image layers (bi-dimensional histograms).

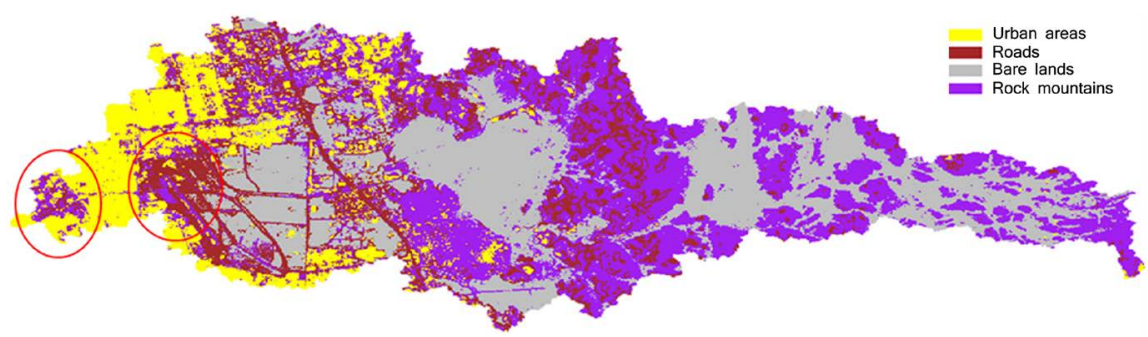

Figure 13. Supervised classification of Landsat image (1985).

channels is unsatisfactory because of the strong correlation between different spectral responses of different classes, the main idea is to generate new channels each carrying a quantity information dedicated to the detection of a particular phenomenon and to minimize the correlation between the channels. This workflow is illustrated by Figure 14 .

On the basis of this idea, a set of indices has been generated for each image, in this case, the following indices:

\subsubsection{Urban Index (UI)}

The urban index (UI) is used to a high speed mapping of built-up areas. But the single usage of this index is to enable to verify the distribution of built-up vs. bare land areas. This index is defined as:

$$
\mathrm{UI}=\frac{\mathrm{SWIR}-\mathrm{NIR}}{\mathrm{SWIR}+\mathrm{NIR}}
$$

with SWIR: short wave infrared layer and NIR: Near infrared Layer.

\subsubsection{Normalized Difference Vegetation Index (NDVI)}

Normalized Difference Vegetation Index (NDVI) is an index which measures this difference, providing a measure of vegetation density and condition. It is 


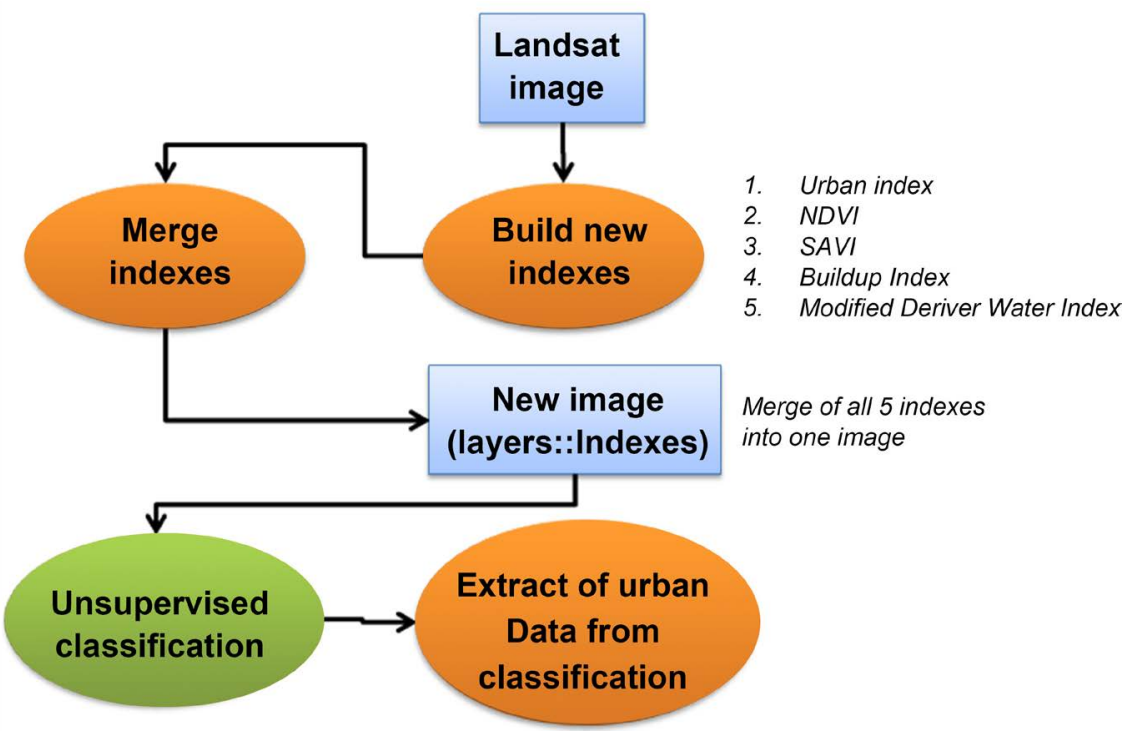

Figure 14. Workflow of the methodology used to extract the Urban Area.

influenced by the fractional cover of the ground by vegetation, the vegetation density and the vegetation greenness. It indicates the photosynthetic capacity of the land surface cover.

NDVI is calculated from the red and near-infrared reflectance RED and NIR as:

$$
\mathrm{NDVI}=\frac{\mathrm{NIR}-\mathrm{RED}}{\mathrm{NIR}+\mathrm{RED}}
$$

Its value is always between -1 and +1 . NDVI decreases as leaves come under water stress, become diseased or die. Bare soil and snow values are close to zero, while water bodies have negative values.

\subsubsection{Soil-Adjusted Vegetation Index (SAVI)}

For extracting and highlighting the areas covered by vegetation, there are several indices; best known by most researchers is the NDVI. However, the NDVI is an index that is satisfactory if and only if a third of the study area is covered by vegetation [11]. Given that our area is sparsely covered by vegetation it opted for the use of the SAVI index because is more sensitive than NDVI in detecting vegetation in the low plant-covered areas. SAVI is defined as follows:

$$
\mathrm{SAVI}=\frac{(\mathrm{NIR}-\mathrm{RED}) *(1+l)}{\mathrm{NIR}+\mathrm{RED}+l}
$$

where NIR: near infrared reflectance, RED: red reflectance and $l$ is a correction factor ranging from 0 for very high densities of vegetation to 1 for very low densities. Our area is very poorly covered by vegetation, so we assign the value 0.8 to 1.

\subsubsection{Modified Normalized Difference Water Index (MNDWI)}

Initially the Normalized difference water index (NDWI) is defined to delineate open water bodies, which is defined by McFeeters [12] as: 


$$
\mathrm{NDWI}=\frac{\text { GREEN }- \text { NIR }}{\text { GREEN }+ \text { NIR }}
$$

where NIR: infrared reflectance and GREEN: green reflectance.

A new version of this index id was defined by $\mathrm{Xu}$ [13], in which he replaced near infrared reflectance by the medium infrared reflectance to minimize confusion between water bodies and built-up features in the green band. Despite the absence of water bodies in our study area, the use of this index seems very interesting to differentiate bare soils in relation to their degree of moisture.

The model shown below was developed as part of this study to calculate all previously defined indices and merge them into a single image and in fine classify the merged image to highlight and extract urban areas as shown in Figure 15.

The following figures (Figures 16-19) illustrate some outputs of the model, such as Urban Index, NDVI Index, Savi Index and MNDWI Index.

For each year, produced indexes are merged into one stacked image in Figure 20.

After unsupervised classification of all indices images, classes representing urban areas are extracted. Figure 21 illustrates extension of urban areas from 1985 to 2015.

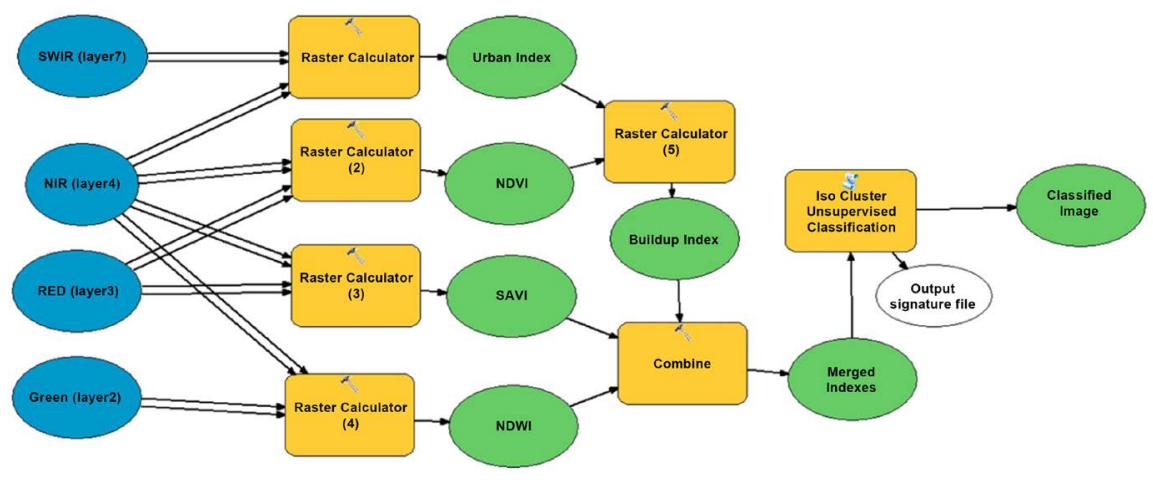

Figure 15. Production of index-derived images.

Urban Index (UI)

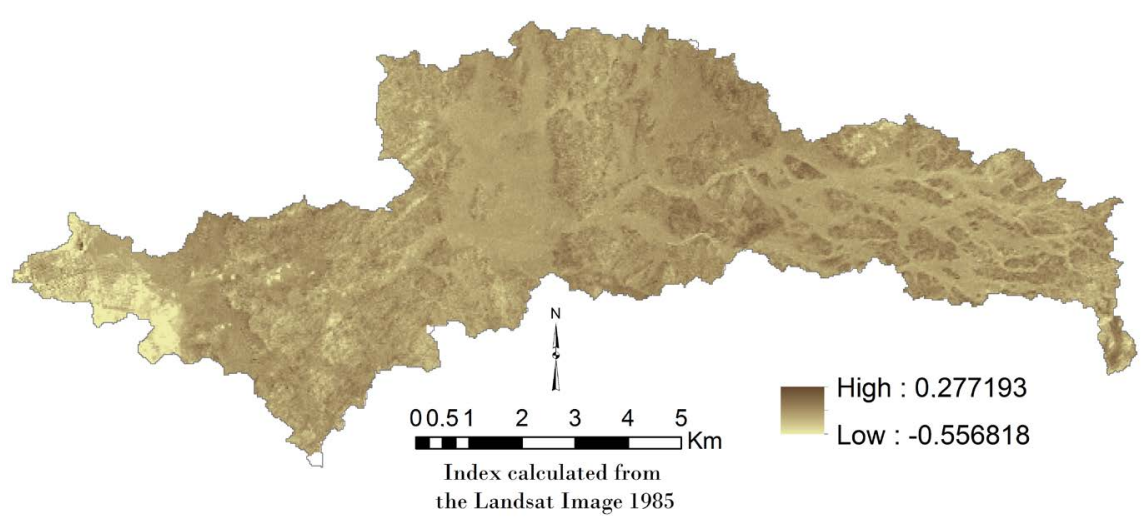

Figure 16. Urban index (1985). 
Normalized Difference Vegetation Index (NDVI)

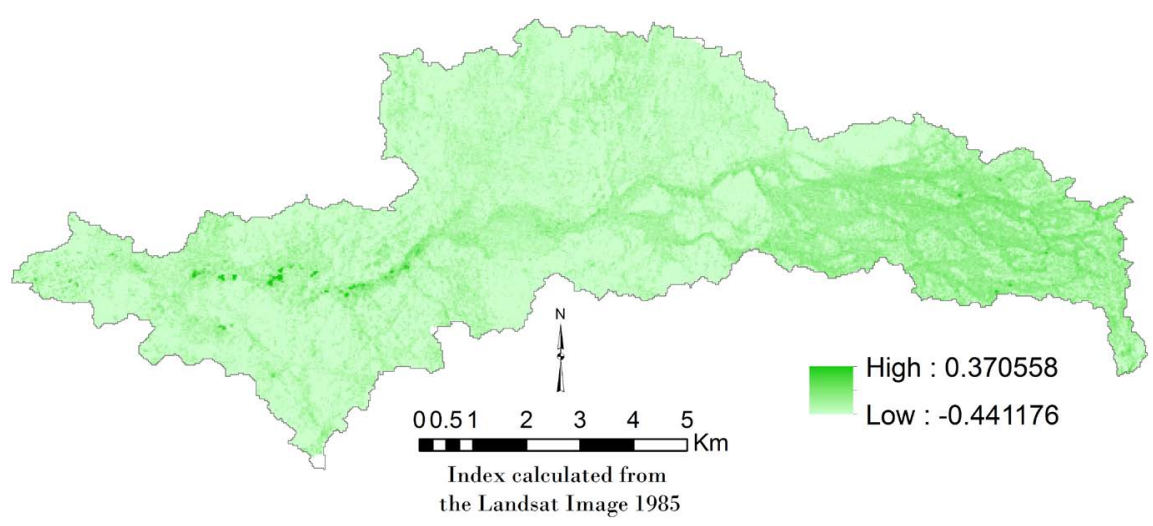

Figure 17. NDV index (1985).

Modified Normalized Difference Water Index (MNDWI)

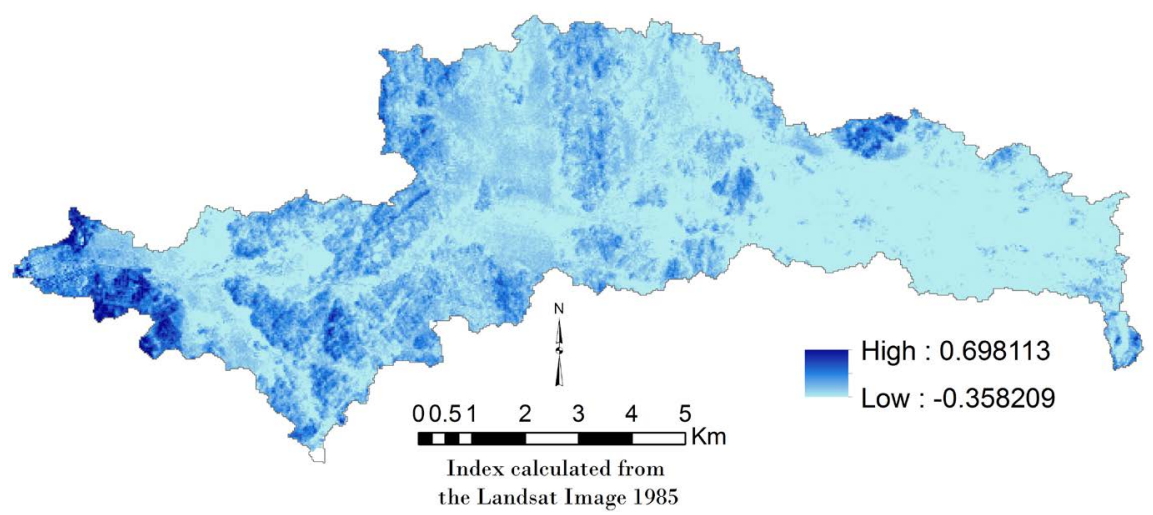

Figure 18. MNDW index (1985).

\section{Soil-adjusted Vegetation Index (SAVI)}

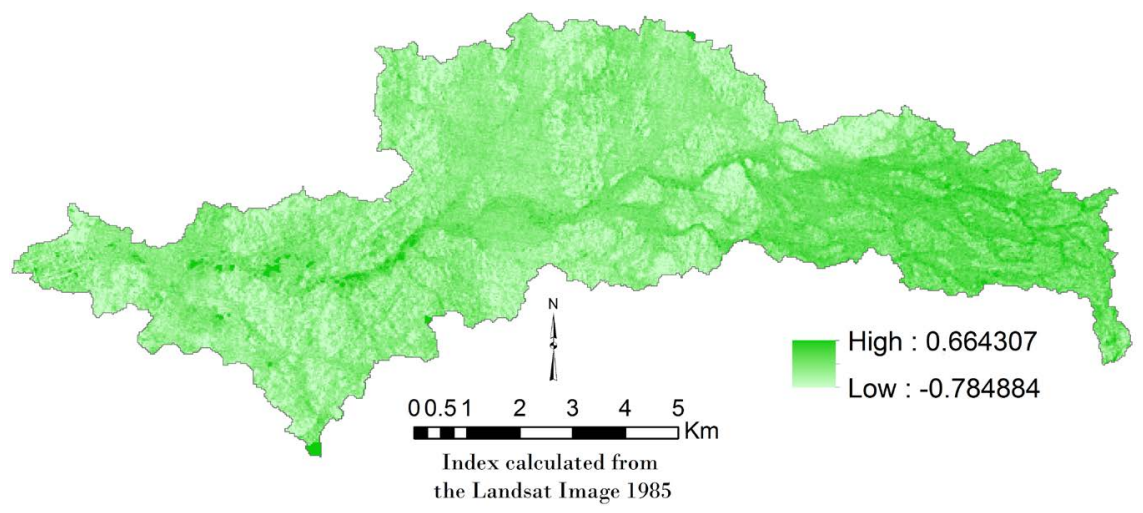

Figure 19. Sav index (1985).

The buildings have been significantly increased over the last 30 years as each contract doubled For example, in 1990, the buildings was 192.8 hectares after one decade in 2000, it became 284.5 hectares. In 2010, in one decade, the buildings 


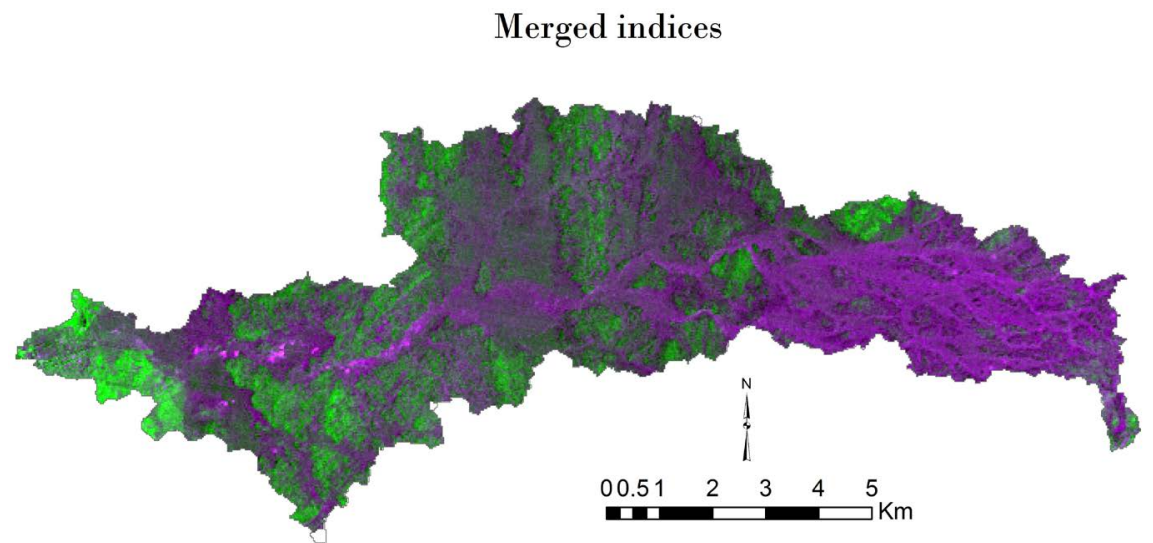

Figure 20. Merged indices.
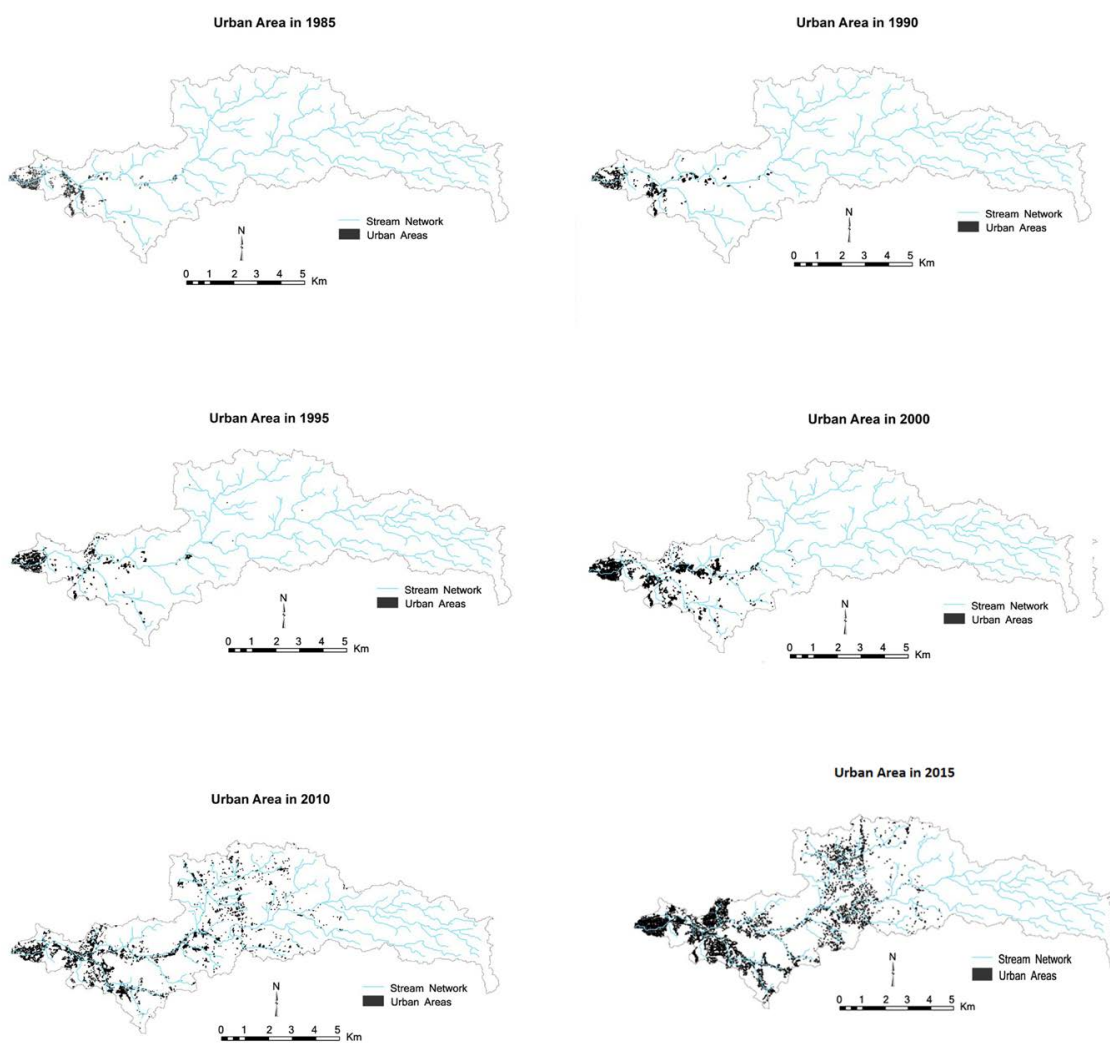

Figure 21. Extension of urban areas from 1985 to 2015.

doubled again to 498.7 hectares. Figure 22 shows the increase of the built-up areas during three decades.

The percentage of buildings in Wadi Goss in 1985 was $2 \%$ of the total area of the watershed and increase to $12 \%$ in 2015 , which indicates that the region is still in urban growth.

The results obtained concerning urban extension show clearly that the extension was operated mainly in the lower areas especially near streams. As we have rather indicates the risk being defined as a combination of randomness, the vulnerability and exposure, we note that the new buildings are increasingly exposed, 
given their positions near streams, which increases considerably the risk of being flooded.

Figure 23 was undertaken after crossing streams of order 3, 4 and 5 that could be considered as areas of high water accumulation, with current urban areas as areas at high risk of flooding are represented in red.

The risk depends on three factors are (Hazard, Exposure and Vulnerability) as shown in Figure 8. And also runoff is increasing with urban growth according to previously proven theory Figure 9 with these two theories, risk areas were identified in red as shown in Figure 23. The watershed is almost completely urbanized which induces a runoff of $50 \%$ of the precipitated amounts, which increases the risk of flooding, especially in the absence of a network to eliminate excess rainwater. However, it would be better to study this watershed using the techniques of urban hydrology in order to gain a better understanding of the operating mode of the water routing in urban areas.

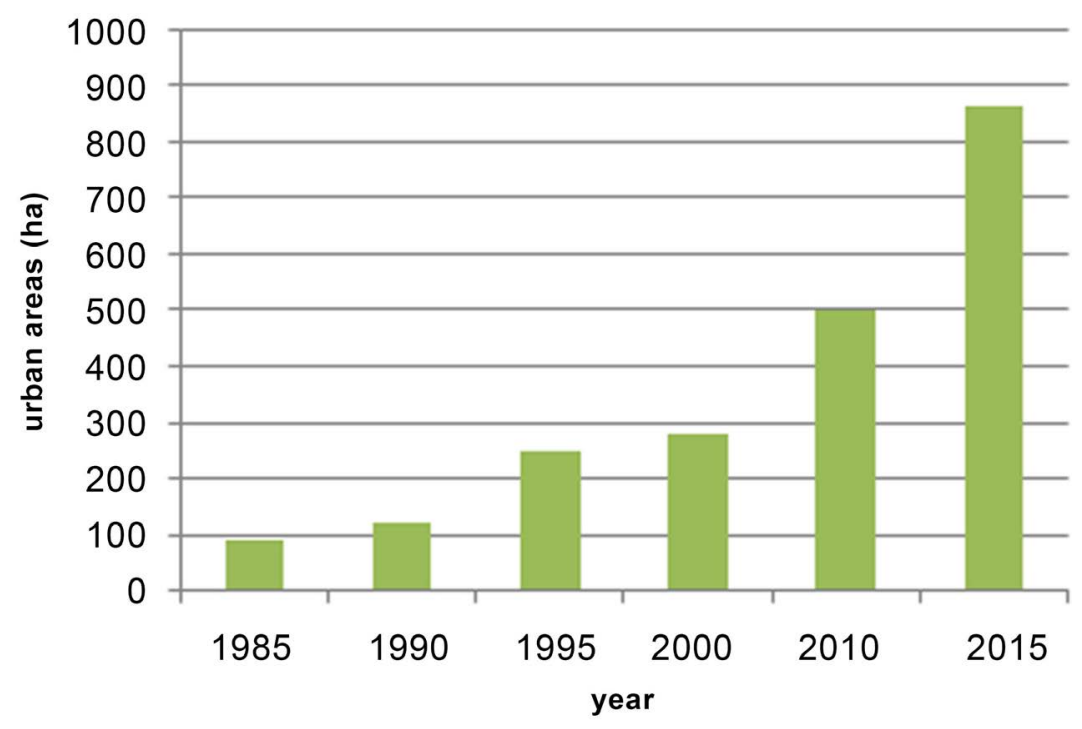

Figure 22. Growth of urban areas between 1985 and 2015.

\section{Areas at Risk of flooding}

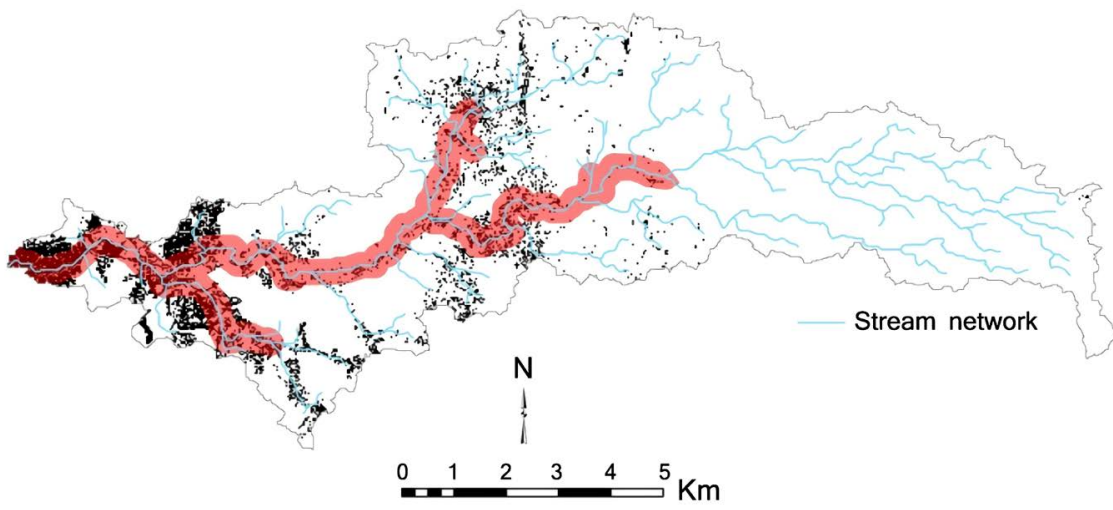

Figure 23. Areas at risk of flooding. 
The study carried out by El-Hames et al. [14]. in which they try to reconstruct the flood occurred in Gueeza town (the western urban area of the watershed) on November 25, 2009, shows that the time of concentration was found about 1.6 hours (under wet conditions) and a discharge of $400 \mathrm{~m}^{3} / \mathrm{s}$. this produced a water level in the Gueeza town extremely high ( $2.1 \mathrm{~m}$ observed).

\section{Conclusions and Discussions}

The purpose of this work was to study the urban sprawl within the Wadi Goss watershed, in order to highlight the areas at the risk of floods. The Wadi Goss watershed was considered to be one of the most violent and this fact was observed during the floods of 2009 and 2011. We have estimated the morphometric characteristics of this watershed, and it is clear that except for the length of its mainstream, which is about $25 \mathrm{~km}$ long, the watershed is of order 5 following a classification of its hydrographic network according to Strahler's classification. All these characteristics make the mainstream, as well as surrounding areas as areas at high risk of flooding.

To follow the evolution of the urbanization inside the basin we used the Landsat images over a period of 30 years (going from 1985 to 2015). We have shown that the urban footprint inside the watershed is about 850 hectares and occupies $12 \%$ of the total watershed area in 2015, while it was about 90 hectares in 1985 ( $2 \%$ of the watershed area). This clearly shows the sustained evolution of the urban within this watershed that is mingling with the city of Jeddah. With the increasing urbanization, some houses have become located inside the many Wadis, as well as drainage channels were weak which led to the growing problem.

It is clear that the higher population growth led to higher runoff. Therefore, the solutions currently imposed by Saudi Arabia now may not be appropriate in the future as the urban growth in the region increases. So that drainage channels can be established prior to housing construction and that the construction should be non-random.

To solve problems and reduce the risk, we recommend for future work in order to achieve more accurate results:

- Build an infrastructure including drainage and sewage networks for future new development areas, especially in the western part of the watershed (Gueeza city), where urbanization is continuing at pace.

- Remove existing buildings in the flood and the best way to cope with floods is to direct or redirect flood waters towards the sea and connect them to the floodplain until they flow into the Red Sea from east to west.

\section{Conflicts of Interest}

The authors declare no conflicts of interest regarding the publication of this paper.

\section{References}

[1] Youssef, A.M., Sefry, S.A., Pradhan, B. and Alfadail, E.A. (2016) Analysis on Causes 
of Flash Flood in Jeddah City (Kingdom of Saudi Arabia) of 2009 and 2011 Using Multi-Sensor Remote Sensing Data and GIS. Geomatics, Natural Hazards and Risk, 7, 1018-1042. https://doi.org/10.1080/19475705.2015.1012750

[2] EM-DAT: The OFDA/CRED (2010) International Disaster Data Base. Université catholique de Louvain, Brussels, Bel. Data version: v11.08.

http://www.emdat.be/

[3] Al Saud, M. (2012) Use of Remote Sensing and GIS to Analyze Drainage System in Flood Occurrence, Jeddah-Western Saudi Coast. In: Javaid, M.S., Ed., Drainage Systems, InTech, 139-164. https://doi.org/10.5772/34008

[4] Al Saud, M. (2009) Watershed Characterization of Wadi Aurnah, Western Arabian Peninsula. Journal of Water Resource and Protection, 1, 316-324.

https://doi.org/10.4236/jwarp.2009.15038

[5] Al Saud, M. (2010) Assessment of Flood Hazard of Jeddah Area 2009, Saudi Arabia. Journal of Water Resource and Protection, 2, 839-847. https://doi.org/10.4236/jwarp.2010.29099

[6] Subyani, A.M. (2004) Geostatistical Study of Annual and Seasonal Mean Rainfall Patterns in Southwest Saudi Arabia/Distribution Géostatistique de La PluieMoyenne Annuelle et Saisonnière Dans Le Sud-Ouest de l'Arabie Saoudite. Hydrological Sciences Journal, 49, 817. https://doi.org/10.1623/hysj.49.5.803.55137

[7] Crichton, D. (1999) The Risk Triangle. In: Ingleton, J., Ed., Natural Disaster Management, Tudor Rose, London, 102-103.

[8] Faccini, F., et al. (2018) Role of Rainfall Intensity and Urban Sprawl in the 2014 Flash Flood in Genoa City, Bisagno Catchment (Liguria, Italy). Applied Geography, 98, 224-241. https://doi.org/10.1016/j.apgeog.2018.07.022

[9] Su, M., et al. (2018) The Influence of Landscape Pattern on the Risk of Urban Water-Logging and Flood Disaster. Ecological Indicators, 92, 133-140. https://doi.org/10.1016/j.ecolind.2017.03.008

[10] Boulomytis, V.T.G., Imteaz, M.A., Zuffo, A.C. and Alves, C.D. (2016) Analysis of the Urbanization Effects on the Increase of Flood Susceptibility in Coastal Areas. Theoretical and Empirical Researches in Urban Management, 11, 30-45.

[11] Ray, T.W. (1994) Vegetation in Remote Sensing FAQ's Applications. ER Mapper, LTD, Perth, Unpaginated CDROM.

[12] McFeeters, S.K. (1996) The Use of Normalized Difference water Index (NDWI) in the Delineation of Open Water Features. International Journal of Remote Sensing, 17, 1425-1432. https://doi.org/10.1080/01431169608948714

[13] Xu, H. (2005) A Study on Information Extraction of Water Body with the Modified Normalized Difference Water Index (MNDWI). Journal of Remote Sensing, 9, 511-517.

[14] El-Hamed, A.S. and Al-Wagdany, A.S. (2012) Reconstruction of Flood Characteristics in Urbanized Arid Regions: Case Study of the Flood of 25 November 2009 in Jeddah, Saudi Arabia. Hydrological Sciences Journal, 57, 507-516, https://doi.org/10.1080/02626667.2012.665995 